\title{
Paisaje cultural de la Zona del Canal: un patrimonio por reconocer, valorar y proteger. Caso estudio del Fuerte Clayton
}

\author{
Alba, Almyr \\ Universidad de Panamá \\ Panamá, Panamá \\ almyr.alba@up.ac.pa \\ Arosemena, Graciela \\ Universidad de Panamá \\ Panamá, Panamá \\ graciela.arosemena@up.ac.pa
}

\section{Abstract}

The Panama Canal Zone is a landscape unit made up of vast forested areas, civilian and military settlements, and industrial zones related to the interoceanic route through Panama. This cultural landscape forms a unique cultural legacy in the region, whose protection relays on its recognition and appreciation by the public. The objective of this study was to document the historical evolution and heritage value through a selected a case study of Fort Clayton. A site comprising typical architectural and landscape features of the former Canal Zone, showing signs of authenticity and integrity from a heritage perspective.

The methodology consisted of a historiographic study through the analysis of documentary sources related to the architecture, urban planning and history of the Canal Zone. Complemented with the analysis of on-site material evidence to trace the historical evolution of the Clayton's urban features and to analyze their level of authenticity and integrity. The research was enhanced by an exploration on the values attributed to heritage by North Americans and Panamanians aproched by documentary investigation and focus group.

The results allowed to establishs a chronology of distinctive qualities of the cultural landscape and its parallel to North American military and suburban sites, and to determine intermediate range of authenticy and integrity of heritage attributes. Regarding the 
appraisal of this heritage, the governments of Panama and the United States recognized its relevance at 1990's decade. Meanwhile, the public, approached in the study, attributes symbolic values to built world and general high appreciation to the landscape.

Keywords: Cultural landscape, Canal Zone, heritage value, integrity and autenticity.

\section{RESUMEN}

LaZona del Canal es una unidad de paisaje conformada por bastas áreas de bosques, poblados civiles y militares y zonas industriales relacionadas el manejo de la ruta interoceánica por Panamá. Este paisaje cultural conforma un legado cultural único en la región cuya protección depende de su reconocimiento y valoración. El objetivo de este estudio fue consecuentemente, documentar la evolución histórica y el valor patrimonial del Fuerte Clayton. Un sitio con elementos representativos de la arquitectura y el paisajismo típicos de la la Zona del Canal que a la vez que muestra un entorno relativamente auténtico e integro desde la perspectiva patrimonial.

La metodología consistió en el estudio historiográfico a través del análisis fuentes documentales de arquitectura, urbanismo e historia de la Zona del Canal. Complementado con trabajo de campo para analizar las evidencias materiales que permitieron identificar la huella de cada etapa histórica del Fuerte. Enriquecido con indagación. sobre la valoración atribuida al patrimonio por los norteamericanos y los panameños mediante investigación documental y grupos focales.

Los resultados permitieron precisar las fechas y características distintivas de los elementos del paisaje cultural y su coincidencia con emplazamientos militares y suburbanos norteamericanos y establecer valores intermedios de autenticidad e integridad. Respecto de la valoración del legado canalero, los gobiernos de Panamá y Estados Unidos reconocieron el patrimonio edificado en la década de 1990. En tanto que, la población, abordada a través de grupos focales, atribuye valores simbólicos al entorno construido y aprecia el paisaje natural de la ex Zona del Canal.

Palabras claves: Paisaje cultural, Zona del Canal, valor patrimonial, integridad y autenticidad. 


\section{INTRODUCCIÓN}

El presente trabajo busca aportar elementos a la discusión sobre del valor del patrimonio de la antigua Zona del Canal y la pertinencia de su protección como paisaje cultural de indiscutible valor nacional e internacional. Un territorio que atestigua sobre de la evolución de la actividad de tránsito que durante siglos han permitido las ventajas geográficas del estrecho territorio entre dos mares que es Panamá. El reconocimiento del legado patrimonial del producido durante el siglo XX con adaptaciones del paisaje y la arquitectura para reducir los riesgos a salud derivados de las enfermedades tropicales depende del sustendo que de la investigación, valoración y ulterior protección para evitar su extinción, como es ya evidente en algunos antiguos poblados canaleros.

El objetivo del estudio fue, consecuentemente, reconocer los componentes del paisaje cultural histórico documentando su evolución a través del tiempo. A la vez que, determinar el valor patrimonial de la arquitectura y el urbanismo de la Zona del Canal para crear las bases para su salvaguarda. El Fuerte Clayton fue seleccionado como un estudio de caso ya que que representa, a modo microcosmos, los diseños arquitectónicos y paísajisticos y las prácticas constructivas típicas de la era norteamericana en toda la Zona del Canal. Además, cuenta con un el estado de conservación aceptable y presenta un entorno relativamemte auténtico e integro.

\section{MÉTODO}

\section{A. Caracterización del paisaje}

El estudio historiográfico abordó la revisión de fuentes documentales primaria y secundaria en archivos norteamericanos y panameños con documentos bibliográficos, gráficos y cartográficos sobre la historia de la Zona del Canal. La documentación consultada permitió reconstruir las etapas de expansión del fuerte y caracterizar los elementos arquitectónicos y paisajísticos que conforman el paisaje cultural del Fuerte Clayton en cada una de las etapas de expansión de esta base militar.

\section{B. Autenticidad e integridad}

La valoración de la autenticidad e integridad garantizan que los bienes patrimoniales son un testimonio inequívoco del pasado histórico. Por un lado, la autenticidad sirve para determinar si la forma y materialidad del bien son originales. Por otro, la integridad determina si el bien está suficientemente intacto para comprender como era originalmente [1]. La autencidad es comprobada bajos los siguientes criterios: cambios del emplazamiento, el diseño de los edificios, el diseño del paisaje, el carácter del sitio, el uso y función, los materiales y las técnicas. La integridad verifica si el sitio contiene todos los elementos para expresar su valor histórico, si dentro de sus límites están contenidos todos los elementos 
del valor histórico y la condición de conservación los elementos arquitectónicos, urbanos y paisajísticos [2]. Su comprobación se hizo a través de una matriz de valoración sencilla, donde los criterios fueron correlacionados con la gradiente de cumplimiento de cada uno de los criterios.

\section{Valoración Patrimonial}

La valoración y posterior protección del patrimonio cultural se sustenta en gran medida en su reconocimiento por parte la población [3]. Para analizar la situación de la valoración del patrimonio canalero consultamos estudios especializados elaborados por Panamá y Estados Unidos. Adicionalmente, para aproximarnos a la valoración de la población se conformaron 5 grupos focales constituidos por los actores sociales norteamericanos y panameños vinculados en el pasado y en el presente con la ex Zona del Canal.

Todos los participantes de los grupos realizaron un foto test [] 4 con 8 imágenes de edificios, infraestructura y del paisaje característico de la ex Zona del Canal (hoy Áreas Revertidas). Los miembros de los grupos relacionaron las imágenes con 3 palabras preseleccionadas conexas con las categorías generales de valores patrimoniales, a saber: formales, de uso y simbólicos [5,6]. Al que se sumó la naturaleza como 4 eje de valoración vinculado del paisaje natural.

\section{RESULTADOS}

\section{A. Caracterizacion del Paisaje}

El análisis de evolución histórica del fuerte permitió determinan las etapas de expansión y su relación con los emplazamientos de defensa y los modelos de suburbanos norteamericanos de inicios del siglo XX y de antes y después de la de la Segunda Guerra Mundial. Los edificios de las etapas iniciales (1922-1943), mayores en número, corresponde al estilo "colonial español" caracterizado por grandes techos de tejas, paredes blancas sin ornamentación y alturas de dos a tres pisos. En tanto que, el paisajismo está definido por amplias zonas de grama, con pocos arbustos, arboles robustos aislados y palmeras alineadas, canales abiertos para el manejo eficiente de la evacuación del agua lluvia. La suma de ambos constituye la imagen dominantes del sitio.

\section{B. Autenticidad e Integridad}

Los resultados de la evaluación de la situación de autenticidad por sectores (ver fig. 1) determinan que la valoración total promedio está dentro de los rangos medios (ver tabla 1). El sector 5 de viviendas construida entre 1940 y 1950 no presenta alteraciones, mientras La Herradura y el área de servicios donde han ocurrido mayor número de demoliciones detentan los rangos bajos de autenticidad. En el caso de la integridad presenta resultados similares, con un promedio total dentro de los rangos medios (ver tabla 2). Los sectores 1, 4 
y 6 muestran valores bajos y medios por la perdida de edificios originales y/o deficiencias de conservación de algunos edificios y el paisaje. En contraposición, el rango más alto ocurre en el sector 5 de viviendas donde los parámetros de integridad no han sido alterados.

Tabla 1. Evaluación de la autenticidad del paisaje cultural del Fuerte Clayton (CDS) por sectores

\begin{tabular}{lcccccc}
\hline $\begin{array}{l}\text { Parámetro de } \\
\text { autenticidad }\end{array}$ & $\begin{array}{c}\text { Sector 1 } \\
\text { La } \\
\text { Herradura }\end{array}$ & $\begin{array}{c}\text { Sector 2 } \\
\text { El } \\
\text { Cuadrángulo }\end{array}$ & $\begin{array}{c}\text { Sector 3 } \\
\text { New Post }\end{array}$ & $\begin{array}{c}\text { Sector 4 } \\
\text { Área de } \\
\text { Servicio }\end{array}$ & $\begin{array}{c}\text { Sector 5 } \\
\text { Viviendas }\end{array}$ & $\begin{array}{c}\text { Sector 6 } \\
\text { Milner's } \\
\text { Field }\end{array}$ \\
\hline Conf. emplazamiento & 1922 & $1932-1950$ & $1940-1945$ & $1930-1945$ & $1940-1950$ & $1932-1950$ \\
\hline Diseño - edificios & 2 & 4 & 5 & 5 & 5 & 5 \\
\hline Diseño - paisajismo & 2 & 4 & 4 & 2 & 5 & 4 \\
\hline Carácter del sitio & 2 & 4 & 3 & 5 & 5 & 5 \\
\hline Uso y función & 2 & 4 & 3 & 2 & 5 & 5 \\
\hline Materiales & 2 & 3 & 3 & 1 & 5 & 5 \\
\hline Técnicas & 2 & 3 & 4 & 3 & 5 & 4 \\
\hline Total & 2 & 4 & 4 & 3 & 5 & 5 \\
\hline Rango de valoración & $\mathbf{1 6}$ & $\mathbf{2 5}$ & $\mathbf{2 5}$ & $\mathbf{1 7}$ & $\mathbf{3 5}$ & $\mathbf{3 3}$ \\
\hline
\end{tabular}

Fuente: Elaboración propia basado en WHC y Ames

Tabla 2. Evaluación de la integridad del paisaje cultural del Fuerte Clayton (CDS) por sectores

\begin{tabular}{|c|c|c|c|c|c|c|}
\hline Parámetro de integridad & $\begin{array}{c}\text { Sector } 1 \\
\text { La } \\
\text { Herradura }\end{array}$ & $\begin{array}{c}\text { Sector } 2 \\
\text { El } \\
\text { Cuadrángulo }\end{array}$ & $\begin{array}{c}\text { Sector } 3 \\
\text { New } \\
\text { Post }\end{array}$ & $\begin{array}{l}\text { Sector } 4 \\
\text { Área de } \\
\text { Servicio }\end{array}$ & $\begin{array}{l}\text { Sector } 5 \\
\text { Viviendas }\end{array}$ & $\begin{array}{c}\text { Sector } 6 \\
\text { Milner's } \\
\text { Field }\end{array}$ \\
\hline & 1922 & $1932-1950$ & $\begin{array}{r}1940 \\
-1945\end{array}$ & $\begin{array}{r}1930 \\
-1945\end{array}$ & $1940-1950$ & $\begin{array}{l}1932 \\
-1950\end{array}$ \\
\hline $\begin{array}{l}\text { Contiene todos los elementos que } \\
\text { expresan su valor }\end{array}$ & 1 & 5 & 5 & 3 & 5 & 4 \\
\hline $\begin{array}{l}\text { La extensión del sitio incluye todos } \\
\text { los elem. que expresan el valor }\end{array}$ & 2 & 5 & 5 & 5 & 5 & 5 \\
\hline $\begin{array}{l}\text { Los elementos arquitectónicos están en } \\
\text { buenas condiciones }\end{array}$ & 5 & 5 & 4 & 2 & 5 & 4 \\
\hline $\begin{array}{l}\text { Los elementos paisajísticos están en } \\
\text { buenas condiciones }\end{array}$ & 3 & 4 & 4 & 5 & 5 & 4 \\
\hline Total & 11 & 19 & 18 & 15 & 20 & 17 \\
\hline Rango de valoración total & bajo & alto & alto & medio & alto & medio \\
\hline
\end{tabular}

Fuente: elaboración propia, basado en WHC y Ames 


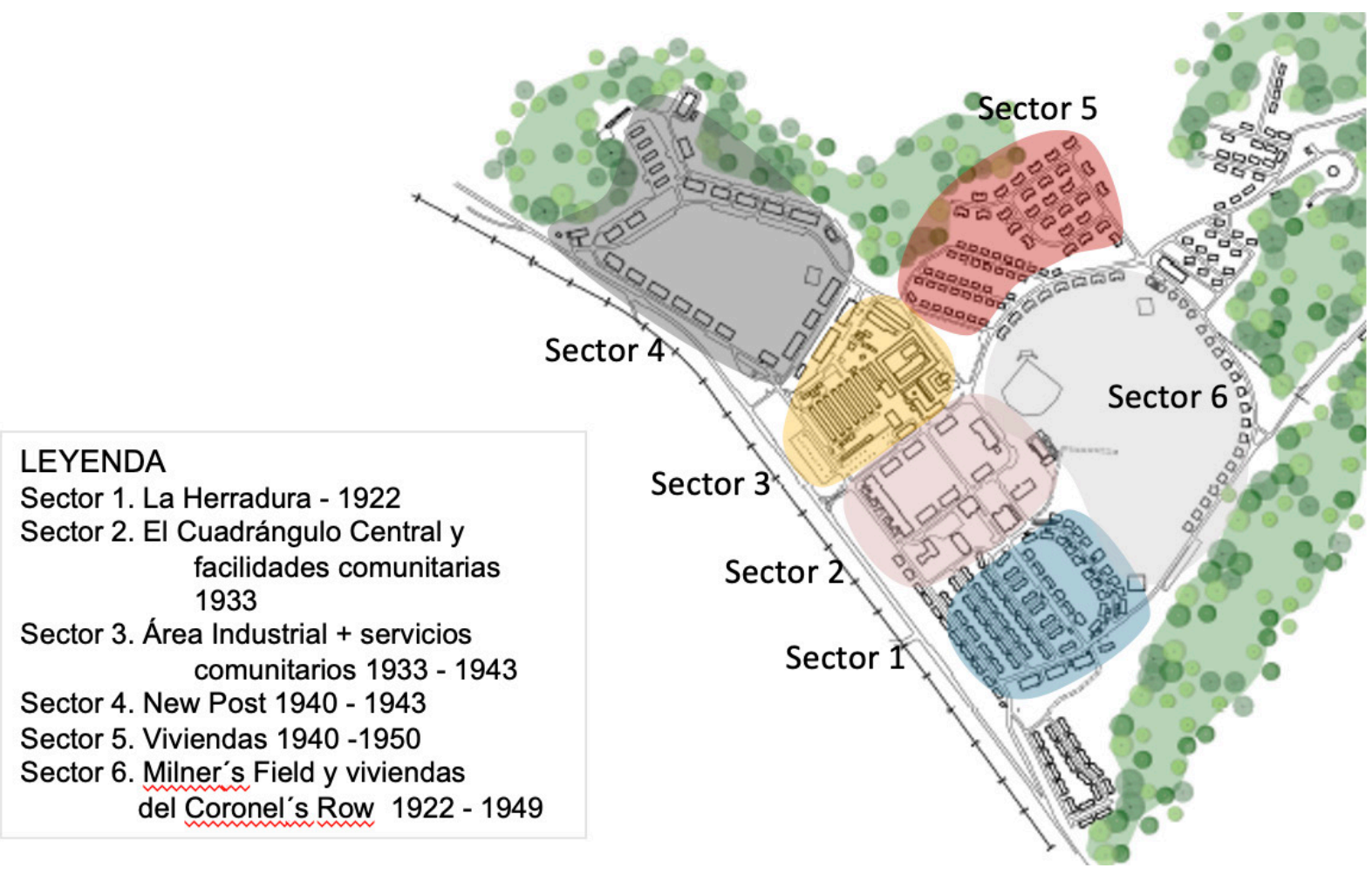

Figura 1: mapa de sectores de análisis de autenticidad de integridad, Fuerte Clayton área de CDS

\section{Valoración del patrimonio}

Los estudios elaborados por Estados Unidos y Panamá en la década de 1990 identificaron bienes culturales de gran valor patrimonial en toda la Zona del Canal. En el caso particular del Fuerte Clayton, los norteamericanos recomendaron la protección de los edificios de calidad arquitectónica y de los conjuntos de edificios de más de 50 años [7]. Por su parte Panamá propuso, entre otros sitios, la protección total del Fuerte Clayton debido a que concentra conjuntos de inmuebles y elementos de diseño urbano con "cualidades únicas" [8]

Los resultados de grupos focales indican que el valor simbólico es el predominante, lo que denota su identificación con el sitio. Entre todos son los norteamericanos que vivieron sus años formativos en la Zona del Canal y los adultos panameños que vivieron años de reclamaciones de la soberanía de panameña en la Zona del Canal, los que más valoran el patrimonio canalero. Cabe también destacar que los individuos más jóvenes tienen marcada preferencia por el paisaje natural. Para los detalles de los resultados del fototest ver la tabla 2 a continuación. 
Tabla 2. Valores patrimoniales atribuidos por los grupos focales

\begin{tabular}{|c|c|c|c|c|c|c|}
\hline $\begin{array}{l}\text { Categoría de } \\
\text { valor }\end{array}$ & $\begin{array}{c}\text { Grupo } 1 \\
\text { (norteamericanos } \\
\text { vivieron en la Z.C) } \\
\%\end{array}$ & $\begin{array}{c}\text { Grupo } 2 \\
\text { (panameños } \\
\text { que trabajaron } \\
\text { en la Z.C). } \\
\%\end{array}$ & $\begin{array}{c}\text { Grupo } 3 \\
\text { (panameños } \\
\text { que viven en } \\
\text { las AR) } \\
\%\end{array}$ & $\begin{array}{c}\text { Grupo } 4 \\
\text { (panameños } \\
\text { adultos que no } \\
\text { viven en AR) } \\
\%\end{array}$ & $\begin{array}{c}\text { Grupo } 5 \\
\text { (panameños } \\
\text { jóvenes que no } \\
\text { viven en AR). } \\
\%\end{array}$ & $\begin{array}{c}\% \\
\text { total }\end{array}$ \\
\hline Forma & 23,7 & 27,8 & 16,6 & 29,7 & 30 & 25,5 \\
\hline Simbólico & 57 & 27,8 & 38,9 & 48,2 & 23,8 & 38,81 \\
\hline Uso & 9,5 & 22,3 & 27,8 & 7,4 & 14,3 & 16,12 \\
\hline Naturaleza & 9,5 & 22,3 & 27,8 & 11,2 & 28,6 & 19,72 \\
\hline
\end{tabular}

\section{CONCLUSIONES}

El estudio de los valores del paisaje cultural de la Zona del Canal demuestra la adaptación de los modelos urbanos norteamericanos al trópico. Las adecuaciones realizadas produjeron una unidad de paisaje conformada por una sencilla arquitectura de aire colonial español y un paisaje de grandes prados, palmeras alineadas, grupos de arboles con un cuidadoso sistema de canales para evacuación del agua lluvia. Al definir la situación de autenticidad e integridad el resultado presenta rangos intermedios para ambos. Respecto de la apreciación del patrimonio en el ámbito gubernamental, Panamá y Estados Unidos reconocieron la importancia de los bienes patrimoniales en la década de 1990. Finalmente, la población indagada reconoció sobretodo los aspectos simbólicos del entorno construido y en general atribuye un valor especial al paisaje natural de la antigua Zona del Canal.

\section{Referencias}

[1] Stovel, Herb. "Effective Use of Authenticity and Integrity as World Heritage Qualifying Conditions". City and Time 2 (3), 2007. [En línea] Disponible en: http://www.ct.ceci-br.org

[2] UNESCO. Operational Guidelines for the Implementation of the World Heritage Convention. París, 2019

[3] Mechato Lara, Fiorella (diciembre de 2020). "Los valores patrimoniales de la Unidad Vecinal Santa Marina en el Callao desde la mirada de residentes y vecinos". Devenir, vol. 7, n¹4, pp. 11-34, jul. dic. 2020.

[4] Kaplan, R., \& Kaplan, S. "The Experience of Nature: A Psychological Perspective". CUP Archive, 1989

[5] B. Appelbaum. Conservation Treatment Methodology. Nueva York. Barbara Appelbaum Books, 2010

[6] J. Ballart. El patrimonio histórico y arqueologico: valor y uso. Barcelona, Ariel Patrimonio Histórico, 1997

[7] IT Corporation. "Historic Properties Management Plan for the USARSO, Republic of Panama, CA". Tampa, Florida, 1996.

[8] Intercarib S.A. y Nathan Associates, Inc. "Plan General de Uso, Conservación y Desarrollo del Area del Canal. Panamá", 1995. 


\section{Autorización y Licencia CC}

Los autores autorizan a APANAC XVIII a publicar el artículo en las actas de la conferencia en Acceso Abierto (Open Access) en diversos formatos digitales (PDF, HTML, EPUB) e integrarlos en diversas plataformas online como repositorios y bases de datos bajo la licencia CC:

Attribution-NonCommercial-ShareAlike 4.0 International (CC BY-NC-SA 4.0) https://creativecommons.org/

licenses/by-nc-sa/4.0/.

Ni APANAC XVIII ni los editores son responsables ni del contenido ni de las implicaciones de lo expresado en el artículo. 